\title{
Düşey Milli Derin Kuyu Pompalarda Anma Çapı ve Su Giriş Kesit Alanının Bazı Pompa Parametrelerine Etkisi
}

\section{Nuri ORHAN ${ }^{1}$, Osman ÖZBEK ${ }^{2}$, Ali Yavuz SEFLEK ${ }^{3}$}

Selçuk Üniversitesi Ziraat Fakültesi Tarım Makineleri ve Teknolojileri Mühendisliği Bölümü

${ }^{1}$ https://orcid.org/0000-0002-9987-1695, ${ }^{2}$ https://orcid.org/0000-0003-0034-9387, ${ }^{3} \mathrm{https}: / /$ orcid.org/0000-0003-1009-6635

凹: nuriorhan@selcuk.edu.tr

\section{ÖZET}

Bu çalışmada üç değişik anma çapına sahip düşey milli pompanın üç farklı su giriş kesit alanları oluşturulmuştur. Sabit kuyu donanımında, her bir pompa ve kesit alanın kuyu düşüm seviyesine $(\Delta)$, gürültü seviyesine $(\mathrm{G})$, şebekeden çekilen güce $(\mathrm{N})$, pompanın toplam dinamik yüksekliğine (TDY), pompa ile teçhiz borusu arasındaki su hızına ( $\left.\mathrm{v}_{1}\right)$ ve pompa su giriş hızına $\left(\mathrm{v}_{2}\right)$ etkileri incelenmiştir. Sabit debi değerinde pompa anma çapı arttıkça düşüm seviyesi yükselmiştir. Debi, pompa ve kesit alanı parametrelerine ve bunların ikili, üçlü interaksiyonlarının düşüm değerlerine uygulanan varyans analizi sonuçları istatistiksel olarak \%1 seviyesinde anlamlı çıkmıştır. Pompalar içerisinde en az düşüm $28.12 \mathrm{~cm}$ ile $\mathrm{M}_{1}$ pompasında en fazla düşüm ise $74.01 \mathrm{~cm}$ ile $\mathrm{M}_{3}$ pompasinda görülmüştür. Su giriş kesit alanları bakımından en fazla düşüm 50.26 $\mathrm{cm}$ ile $\mathrm{KA}_{3}$ 'de görülmüştür. En fazla gürültü seviyesi $81.67 \mathrm{dBA}$ ile $\mathrm{M}_{3}$ pompasında an az ise $72.6 \mathrm{dBA}$ ile $\mathrm{M}_{1}$ pompasinda ölçülmüştür. Genel olarak pompa anma çapı arttıkça gürültü seviyesi artmıştır. Pompaların en yüksek debi değerlerinde $\mathrm{KA}_{2}$ kesit alanında en düşük TDY elde edilmiştir. Pompa anma çapı ile kuyu teçhiz borusu arasındaki uyumun düşüm üzerine etkisinin olduğu saptanmıştır. Kuyu için pompa seçiminde düşük çaplı pompa seçimi düşüm seviyesinin de az olmasina neden olacaktır.

Araştırma Makalesi
$\begin{aligned} & \text { Makale Tarihçesi } \\ & \text { Geliş Tarihi } \quad: 16.07 .2019 \\ & \text { Kabul Tarihi } \quad: 30.09 .2019\end{aligned}$

Anahtar Kelimeler
Derin kuyu pompası
Düşey milli pompa
Düşüm
Pompalarda gürültü

The Effect of Nominal Diameter and Water Inlet Cross-Sectional Area on Some Pump Parameters in Vertical Shaft Deep Well Pumps

\section{ABSTRACT}

In this study, in three different nominal diameters of the shaft pump three different water inlet cross-sectional areas were formed. In fixed well equipment, the effects of each pump and cross-sectional area on well drawdown $(\Delta)$, noise level $(G)$, power drawn from the mains $(\mathrm{N})$, the total dynamic height of the pump (TDY), water velocity ( $\mathrm{v}_{1}$ ) between the pump with the casing pipe, and pump water inlet velocity $\left(\mathrm{v}_{2}\right)$ were investigated. At a constant flow rate, as the pump nominal diameter increases, the drawdown level increased. According to the water inlet cross-sectional area, the highest drawdown was observed in $\mathrm{KA}_{3}$ with $50.26 \mathrm{~cm}$. The highest noise level was measured at the $\mathrm{M}_{3}$ pump $81.67 \mathrm{dBA}$ and the lowest noise level was found at the $\mathrm{M}_{1}$ pump $72.6 \mathrm{dBA}$. In general, as the nominal diameter of the pump increases, the noise level increased. At the highest flow rate of the pumps, the lowest TDY was obtained in the cross-sectional area of $\mathrm{KA}_{2}$. It was found that the harmony between the nominal diameter of the pump and the well-equipping pipe had an effect on the drawdown. Choosing a pump with a low diameter in the selection of the pump for the well will also cause the drawdown level to be low.

\section{Research Article}

$\begin{array}{ll}\text { Article History } & \\ \text { Received } & : 16.07 .2019 \\ \text { Accepted } & : 30.09 .2019\end{array}$

\section{Keywords}

Deep well pump

Vertical shaft pump

Drawdown

Noise in pumps

To Cite : Orhan N, Özbek O, Şeflek AY 2020. Düşey Milli Derin Kuyu Pompalarda Anma Çapı ve Su Giriş Kesit Alanının Bazı Pompa Parametrelerine Etkisi. KSÜ Tarım ve Doğa Derg 23(1): 237-246, DOI: 10.18016/ksutarimdoga.vi.592640 


\section{GİRIŞ}

Tarımsal sulamada yeraltı ve yer üstü su kaynaklarından yararlanılmaktadır. Yer altı su kaynaklarından faydalı bir şekilde yararlanabilmek için düşey milli ve dalgıç tip derin kuyu pompaları yaygın olarak kullanılmaktadır.

Sondaj makinalarıyla açılan kuyuların çapları pompa çapına bağlı olarak seçilir; elektrik motoruyla tahrik etme imkanı varsa elektrik motorunun şekli de pompa çapına uygun olarak seçilmiş olur. Dalgıç pompalar genelde anma çaplarına göre 6" , 8" , 10" ve 14" 'lik dört seri halde imal edilirler. Dalgıç pompalar ile düşey milli pompalar arasındaki temel fark tahrik elemanının yerleştirildiği konumdur. Teçhiz borusu çapı, kurulum ve verimli çalışma için pompayı yerleştirecek kadar yeterli büyüklükte olmalıdır. Teçhiz borusunun pompa nominal çapından iki birim büyük olması istenir (Boonstra ve Soppe, 2006; Driscoll, 2010). Genel olarak, kuyu teçhiz borusu içindeki dikey su hızının, kuyu kayıplarını en aza indirmek için 1,5-2 $\mathrm{m} \mathrm{s}^{-1}$ den daha az olması gerekir.

Pompaların seçimi ve montajı için dinamik seviyenin tespiti son derece önemlidir. Dinamik seviye toplam dinamik yüksekliğin en önemli bileşenlerinden birisi ve derin kuyu pompalarının tipinin belirlenmesinde en önemli ölçüttür. Bunun sonucu olarak da pompanın montaj derinliği ve motor gücü belirleme işlemi yapılmaktadır (Çalışır ve Konak, 1998; Schulz, 2013). Kuyu teçhiz borusu çapı ile pompa anma çapının kuyudaki su seviyesine etkisi bakımından dalgıç pompalar milli pompalara göre daha fazla düşüme neden olmaktadır (1996). Yazar, bunun nedenini, dalgıç pompa motorlarının, kuyu teçhiz borusu çapını tıkamasına bağlamıştır. Çünkü daralan kuyu kesit alanında artan su giriş hızına bağlı olarak meydana gelen kayıpların, düşümün ve buna bağlı olarak kuyudaki su seviyenin daha fazla düşmesine neden olmaktadır. Kurt ve Çalışır (2017) yaptıkları çalışmada, kuyunun üstten beslenmesi durumunda milli pompaların sabit debi değerlerinde pompa anma çapı ile düşüm arasında net bir ilişki olmadığını bildirmişlerdir. Aynı çalışmada dalgı̨̧ pompaların 70 $\mathrm{m}^{3} \mathrm{~h}^{-1}$ sabit debi değerinde pompa anma çapı arttıkça düşüm seviyesinin azaldığını bildirmişlerdir. Derin kuyu test kulesinin üstten beslenmesi durumunda her iki pompa içinde düşüm seviyelerinin düşük olduğu görülmüştür.

Derin kuyu test kulesinin alttan beslenmesi durumunda ve sabit kuyu teçhiz borusunda, farklı anma çaplarına ve su giriş kesit alanına sahip milli pompaların bazı pompaj parametrelerine etkisinin incelenmesi amaçlanmıştır. Bu bağlamda düşey milli derin kuyu pompasının farklı anma çaplarının ve farklı su giriş kesit alanlarının düşüme $(\Delta)$, gürültü seviyesine $(G)$, şebekeden çekilen güce $(N)$, pompanın geliştirdiği toplam dinamik yüksekliğe (TDY), pompa ile teçhiz borusu arasındaki su hızına $\left(\mathrm{v}_{1}\right)$ ve pompa su giriş hızına ( $\left.\mathrm{v}_{2}\right)$ etkileri incelenmiştir.

\section{MATERYAL ve METOD}

\section{Materyal}

Denemeler Selçuk Üniversitesi Ziraat Fakültesi Tarım Makineleri ve Teknolojileri Mühendisliği Bölümü Prof. Dr. Şinasi YETKIN Tarım Makineleri ve Teknolojileri Mühendisliği Uygulama Atölyesinde, 130140 numaralı TÜBİTAK projesi kapsamında yapılan Derin Kuyu Test Ünitesinde yapılmıştır (Şekil 1).
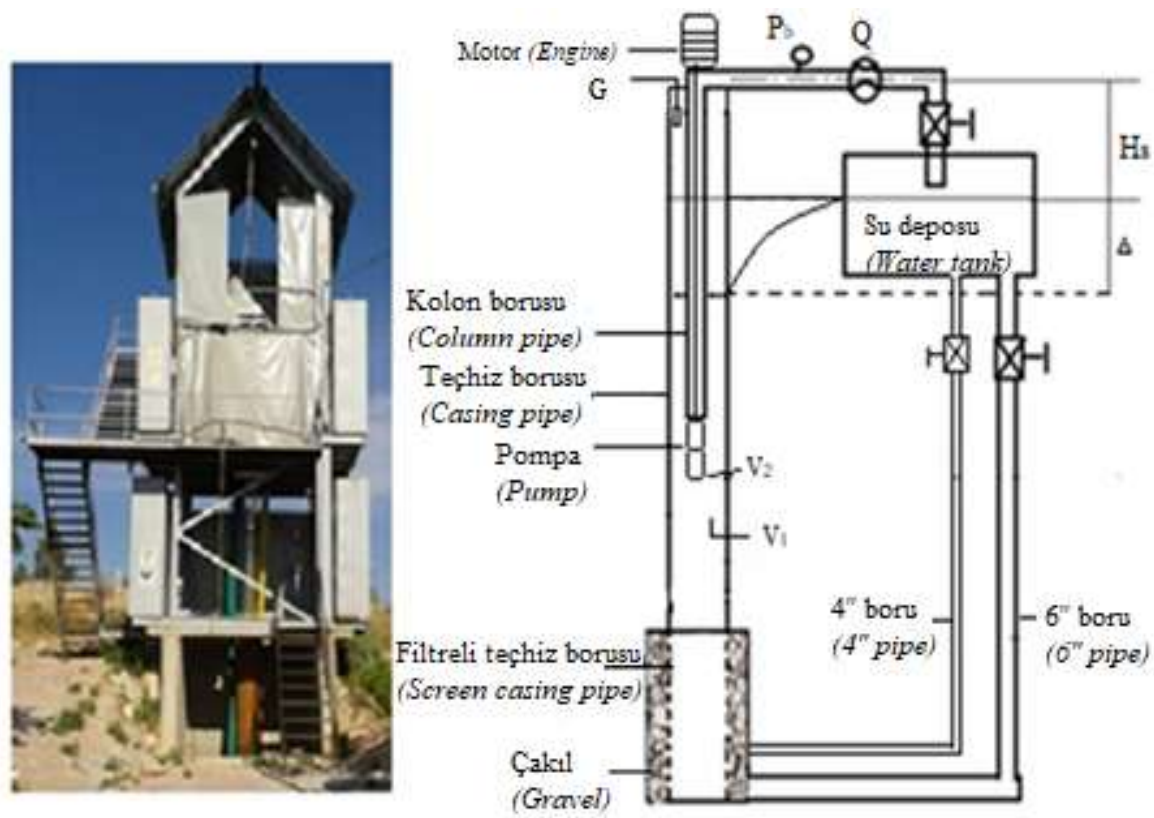

Şekil 1 Derin kuyu test ünitesi ve cihazların bağlantı yerleri

Figure 1. Deep well test unit and connections point of devices. 
Derin kuyu donanımına sahip test düzeneği $10 \mathrm{~m}$ yüksekliğindedir. Test düzeneğinde tabandan itibaren $2 \mathrm{~m}$ oblong delikli filtreli teçhiz borusu, $4 \mathrm{~m}$ kapalı teçhiz borusu ve $4 \mathrm{~m}$ şeffaf teçhiz borusu sabit tutulmuştur. Kuyu donanımı için temiz ve yıkanmış çakıl kullanılmıştır. Çakıl yığını içinden rastgele seçilen 100 adet çakıl örneğinin ölçümleri yapılarak belirlenen bazı fiziksel özellikleri; çakılların uzunluğunun ortalama $19.6 \mathrm{~mm}$, genişliğinin 14.3 $\mathrm{mm}$, kalınlığının $9.1 \mathrm{~mm}$, porozitesinin $\% 44$, küreselliğinin \%70, doğal yığılma açısının $22.76^{0}$ olduğu belirlenmiştir. Ayrıca geometrik çap bakımından deneylerde kulanılan çakılın \%76'sının 7$15 \mathrm{~mm}$ aralıkta olduğu tespit edilmiştir (Akpınar, 1999; Boonstra ve Soppe, 2006). Ayrıca filtreli teçhiz borusunun etrafindaki çakıl genişliği $10 \mathrm{~cm}$ olarak sabit tutulmuştur. Derin kuyu test kulesinin çakıl ve filtre bölümünün olduğu kuyu su giriş kısmı 4" ve 6" borular ile depodan beslenmiştir (Şekil 1).

Deneylerde kullanılan düşey tip derin kuyu pompalarının pompa grubu Şekil 2'de ve pompalara ait bazı teknik özellikler ise Çizelge 1'de verilmiştir.

Çizelge 1. Milli pompaların pompa gruplarına ait bazı teknik özellik ve ölçüleri

Table 1. Some technical features and dimensions of belonging to pump groups of shaft pumps.

\begin{tabular}{|c|c|c|c|}
\hline Teknik özellikler & \multicolumn{3}{|c|}{ Boyutlar } \\
\hline Pompa anma çapı (mm) (Pump nominal diameter) & 78 & 105 & 128 \\
\hline Pompa gövde malzemesi (Material of pump body) & Pik & Pik & Pik \\
\hline Pompa çark malzemesi (Material of pump impeller) & Pirinç & Pirinç & Pirinç \\
\hline Pompa mil malzemesi (Material of pump shaft) & Paslanmaz çelik & Paslanmaz çelik & Paslanmaz çelik \\
\hline Giriş kesit alanı $\left(\mathrm{KA}_{2}\right)\left(\mathrm{cm}^{2}\right)$ (Input cross-sectional area) & 72 & 90 & 108 \\
\hline Pompa mili çapı (mm) (Diameter of pump shaft) & 25 & 25 & 25 \\
\hline Pompa kademe sayısı (Number of pump stage) & 2 & 1 & 1 \\
\hline Klerens açıklığı (mm) (Clearance) & 4.5 & 4.5 & 4.5 \\
\hline Kanat sayısı (adet) (Blade number) & 5 & 5 & 5 \\
\hline Kanat kalınlığg $(\mathrm{mm})$ (Blade thickness) & 5 & 5 & 5 \\
\hline Çark çıkış çapı (mm) (Impeller outlet diameter) & 93.5 & 136 & 150 \\
\hline Çark çıkış genişliği (mm) (Impeller output width) & 15 & 16 & 17.5 \\
\hline
\end{tabular}

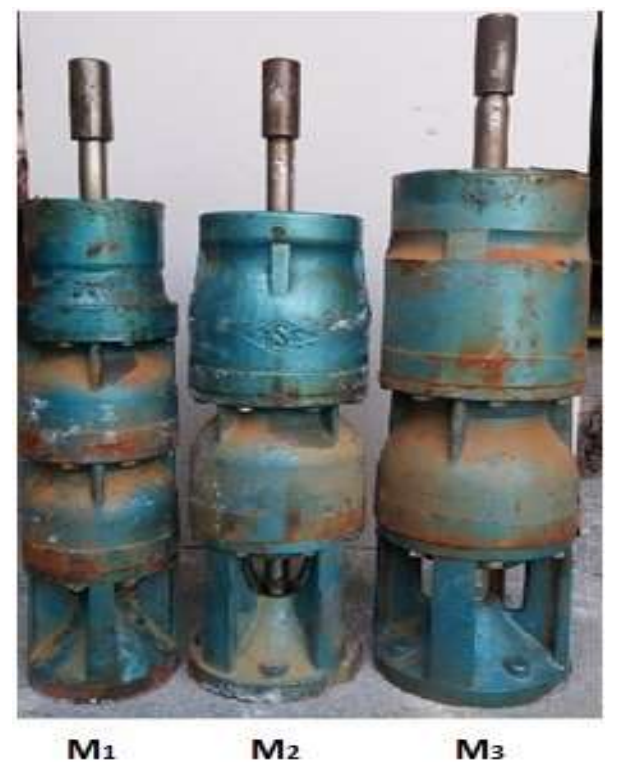

Şekil 2. Deneylerde kullanılan pompaların pompa gruplar

Figure 2. Pump groups of pumps used in experiments

Deneylerde milli pompalarin tahrik edilmesinde kullanılan dik milli elektrik motoru $5.5 \mathrm{~kW}$ gücünde, 11.1 A ve $2910 \mathrm{~min}^{-1}$ olup, Siemens markadır.

Tüm milli pompaların deneme kombinasyonlarında $2000 \mathrm{~mm}$ uzunluğunda bir adet kolon borusu kullanılmıştır. Çalışmada kullanılan ölçüm aletlerinin bazı teknik özellikleri Çizelge 2'de verilmiştir.

\section{Yöntem}

Denemelerde debi, pozitif basınç, şebekeden çekilen güç, akım şiddeti, hız, gürültü, sıcaklıklar ve görüntü gibi fiziksel büyüklük değerlerinin kaydedilmesi için yazılım ve otomasyon sistemi geliştirilmiştir. $\mathrm{Bu}$ sisteminin blok diyagramı Şekil 3'de verilmiştir. Blok diyagramından da görüldüğü gibi sistemde bulunan sensörlerden alınan bilgiler merkezi bir veri toplama kartı üzerinden kablosuz (Bluetooth) olarak Bilgisayar'a aktarılmaktadır. Merkezi işlemcide depolanan bilgiler bilgisayarda hazırlanan yazılım arayüzü aracılığı ile operatör tarafından istenilen aralıklarda uygun isimlerle kayıt edilirler. Kayıt etme işlemi, saniyede birer adet verileri alabilecek tarzda hazırlanmıştır. Pompa rejime girdikten sonra kayıt işlemine başlanılmış ve bir sensör den 50 adet veri alınmıştır. Alınan bu verilerin ortalamaları çizelge olarak verilmiştir.

Blok diyagramında da görüldüğü gibi sistemde bulunan sensörlerlerden alınan bilgiler, merkezi veri toplama kartı üzerinden kablosuz (Bluetooth) olarak bilgisayara aktarılmaktadır.

Pompaların optimum çalışma devrinde ve her bir pompanın 5 değişik debi aralığında ölçümler alınmıştır. Pompa belirlenen herhangi bir debi değerinde çalıştırılarak ilk değerler kayıt altına alındıktan sonra diğer debi değerine geçilmiştir. Bu şekilde beş farklı debi değerinde ölçümler kayıt edilmiştir. 
Pompa 1880 mm sabit hidrolik yük altında denemelere başlanılmıştır. Pompa işletme karakteristiklerinin ölçülmesinde ve yapılan hesaplamalarda ilgili standartlar ve literatür dikkate alınmıştır (Tezer, 1978; Baysal, 1979; Atmaca, 1998; Hanson, 2000; Karassik ve ark., 2001; Anonim, 2002; Çalışır, 2009).

Pompaların orijinal giriş ağzı kesit alanına ek olarak, kesit alanını büyütmek için bir adet daha alt adaptör kullanılmıştır. Bu adaptöre geçirilen burç yardımıyla küçük kesit elde edilmiştir (Şekil 4). Çizelge 3'de kesit alanlarının (KA) büyüklükleri verilmiştir.
Pompaların farklı kesit alanlarına, pompanın alt adaptörlerine, kesit şekli bozulmaksızın müdahale edilerek hazırlanmıştır. Pompaların, farklı her bir anma çapı için birer adet (toplam 6 adet) alt adaptör temin edilmiştir. Bunlardan birer tanesi her bir pompa için orijinal kesit alanına sahip $\left(\mathrm{KA}_{2}\right)$ alt adaptör olarak kullanılmıştır. Diğer her bir alt adaptör, pompa anma çapı için orijinal kesit alanına göre yaklaşık \%20 daha büyük kesit alanı oluşturacak şekilde genişletilerek $\mathrm{KA}_{3}$ ölçülerinde elde edilmiştir.

Çizelge 2 Kullanılan ölçme aletlerinin bazı teknik özellikleri

Table 2. Some technical features of measuring instruments used

\begin{tabular}{|c|c|}
\hline Ekipman cinsi & Bazı teknik özellikleri \\
\hline Debimetre (Flowmeter) & $\begin{array}{l}\text { S MAG } 100 \text { TİP, DN 80-100-125 flanş bağlantılı elektromanyetik debimetre, } 220 \mathrm{~V} \text { beslemeli } \\
\text { dijital göstergeli, anlık debi, yüzde akış ve toplam gösterimli. Ayarlanabilir 4-20 m/A plus ve } \\
\text { frekans çıkışlı. Ölçüm hatası \%0.5 }\end{array}$ \\
\hline Manometre (Manometer) & WİKA, 0-10 bar, Alttan Bağlantılı, 4-20 m/A çıkışlı. \\
\hline Seviye ölçer (Level meter) & Hydrotechnik marka, 010 tip/1.5 V, 150 m’lik ölçeklendirilmiş kablolu, ses ve ışık ikazlı tip. \\
\hline Hız ölçer (Velocimeter) & FLS marka, F3.00 kanatlı tip, ölçüm aralığı $0.1-8 \mathrm{~m} \mathrm{~s}^{-1}$, doğruluk $\pm \% 0.75$, çıkış tipi puls. \\
\hline $\begin{array}{l}\text { Sicaklık sensörleri } \\
\text { (Temperature sensors) }\end{array}$ & Turck marka, 10-24 VDC, $-50 \ldots 100{ }^{0} \mathrm{C}, 4-20 \mathrm{~mA}$ output. \\
\hline Bilgisayar (Computer) & core i7 \\
\hline
\end{tabular}

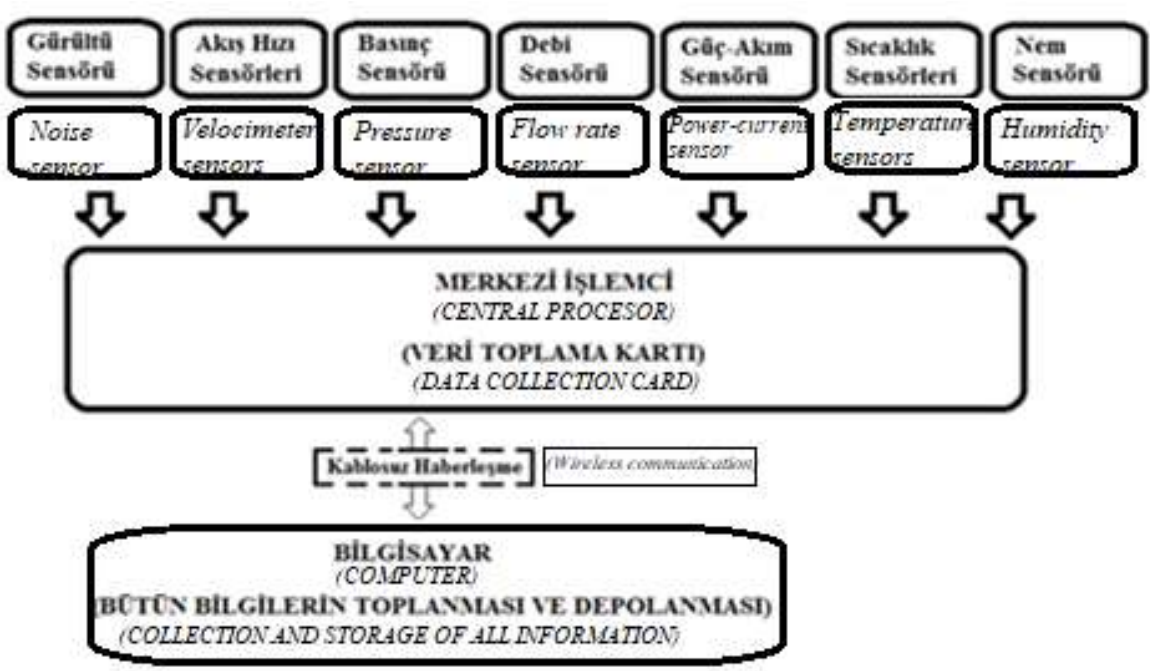

Şekil 3. Otomasyon sisteminin blok diyagramı

Figure 3. Block diagram of the automation system

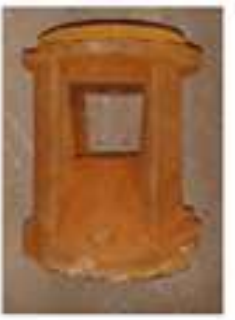

Genį̧letilmiş alt adaptör

(Expancied iower adapter)

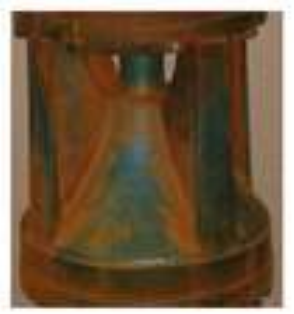

b

Orijinal alt adaptō

(Original iover adapter) (Lower adiapter with apparahis) (apparatis)

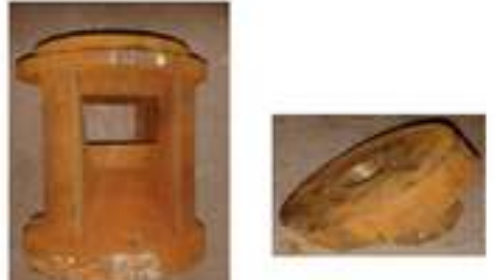

$c$

Şekil 4 Pompaların alt adaptörleri ve giriş ağzı kesit alanı değiştirme burcu

Figure 4. The pump bottom adapters and inlet cross - sectional area replacement apparatus 
Çizelge 3 Pompalar ve pompa giriş kesit alanları $\left(\mathrm{mm}^{2}\right)$

Table 3. Pumps and pump inlet cross ${ }^{-}$sectional areas

\begin{tabular}{llll}
\hline $\begin{array}{l}\text { Pompalar } \\
\text { (Pumps) }\end{array}$ & $\begin{array}{l}\mathrm{KA}_{1} \\
(\% 20 \text { küçük) } \\
(\% 20 \text { small) }\end{array}$ & $\begin{array}{l}\mathrm{KA}_{2} \\
\text { (Orjinal) } \\
\text { (Orginal) }\end{array}$ & $\begin{array}{l}\mathrm{KA} 3 \\
(\% 20 \text { büyük) } \\
(\% 20 \text { larger })\end{array}$ \\
\hline $\mathrm{D}_{1}$ & 3800 & 4800 & 5800 \\
$\mathrm{D}_{2}$ & 7200 & 9000 & 10800 \\
$\mathrm{D}_{3}$ & 13500 & 16800 & 20000 \\
\hline
\end{tabular}

Diğer taraftan yine her anma çapına göre genişletilmiş pompa alt adaptörü için orijinal kesit alanına göre yaklaşık \%20 daha küçük kesit alanı oluşturacak şekilde işlenen sökülebilir bir burç yapılmış ve $\mathrm{KA}_{1}$ ölçüsü elde edilmiştir.

Denemelerin her bir pompanın ve bir pompa besleme ağzı giriş alanı için oluşturulan deneme planları Şekil 5'de verilmiştir.

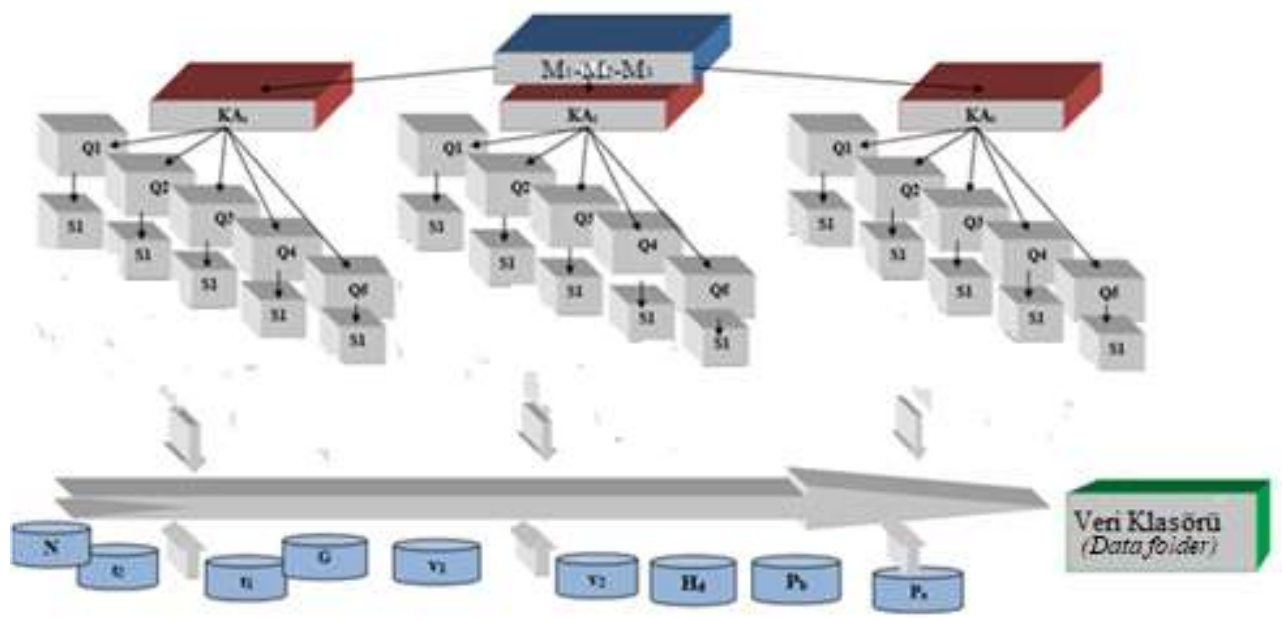

Şekil 5. $\mathrm{M}_{1}-\mathrm{M}_{2}-\mathrm{M}_{3}$ pompalarının deneme deseni

Figure 5. Test design of $M_{1}-M_{2}-M_{3}$ pumps

\section{BULGULAR ve TARTISSMA}

Denemeler süresince ortam sicaklığı ortalaması $20{ }^{\circ} \mathrm{C}$ ve suyun ortalama sicaklığı ise $17{ }^{\circ} \mathrm{C}$ ölçülmüştür. Denemelere başlamadan önce pompalar $188 \mathrm{~cm}$ sabit hidrolik yük ve $89 \mathrm{~cm}$ statik su seviyesi yüksekliklerine ayarlamış ve daha sonra çalıştırılmıştır.

Araştırmada pompaların farklı anma çapları ve kesit alanlarında kuyuda meydana gelen düşüm $(\Delta)$, kuyu içindeki gürültü seviyesi $(G)$, şebekeden çekilen güç (N), toplam dinamik yükseklik (TDY), v1 ve v2 hız parametrelerine etkisi incelenmiştir.
Pompa anma çapı ve su giriş kesit alanının düşüme etkisi

Pompaların üç anma çapında ve su giriş kesit alanında kuyuda meydana getirdiği düşüm $(\Delta)$ seviyeleri Çizelge 4'de verilmiştir.

Çizelge 4'ün incelenmesiyle, pompalardaki tüm kesitlerdeki debi değeri attıkça, düşüm değerleri yükselme eğilimi göstermiştir. Sabit debi ve giriş kesit alanlarında pompaların anma çapı $\mathrm{M}_{1}$ 'den ve $\mathrm{M}_{3}$ 'e büyüdügünde, kuyuda meydana gelen düşüm değerleri artmıştır. Yapılan ilgili çalışmalarda da kuyu kesit alanın daralmasının kuyudaki su seviyenin daha fazla düşmesine neden olduğu bildirilmiştir (Ertöz, 1996; Kurt ve Çalışır, 2017).

Çizelge 4. Pompalardan elde edilen düşüm değerleri (cm)

Table 4. Drawdown values obtained from pumps

\begin{tabular}{llllllllll}
\hline $\mathrm{Q}$ & $\mathrm{M}_{1}$ & \multicolumn{3}{c}{$\mathrm{M}_{2}$} & \multicolumn{3}{c}{$\mathrm{M}_{3}$} \\
\hline$\left(\mathrm{m}^{3} \mathrm{~h}^{-1}\right)$ & $\mathrm{KA}_{1}$ & $\mathrm{KA}_{2}$ & $\mathrm{KA}_{3}$ & $\mathrm{KA}_{1}$ & $\mathrm{KA}_{2}$ & $\mathrm{KA}_{3}$ & $\mathrm{KA}_{1}$ & $\mathrm{KA}_{2}$ & $\mathrm{KA}_{3}$ \\
\hline 40 & 29.8 & 28.1 & 30.8 & 30.0 & 33.0 & 31.0 & 35 & 31 & 35 \\
45 & 37.1 & 36.1 & 37.9 & - & - & - & - & - & - \\
50 & 44.0 & 44.0 & 46.6 & 46.5 & 51.0 & 47.5 & - & - & - \\
55 & 52.7 & 52.9 & 55.5 & - & - & - & - & - & - \\
60 & 61.3 & 62.0 & 65.0 & 66.0 & 70.5 & 67.0 & 74 & 71 & 73 \\
70 & - & - & - & 91.0 & 97.0 & 90.0 & - & - & - \\
80 & - & - & - & 117.0 & 122.5 & 114.5 & 124 & 121 & 123 \\
90 & - & - & - & - & - & - & 157 & 165 & 152 \\
\hline
\end{tabular}

Pompaların anma çaplarında, su giriş kesit alanlarında ve tüm akışın görüldüğü 40 ve $60 \mathrm{~m}^{3} \mathrm{~h}^{-1}$ debi değerlerinde elde edilen düşüm seviyeleri Çizelge 5'de verilmiştir. Debi, pompa anma çapı arttıkça genel olarak düşüm seviyesi değerleri artma eğilimi göstermiştir. Ancak kesit alanı ortalamalarına 
baktığımızda genel olarak orijinal kesit alanında $\left(\mathrm{KA}_{2}\right)$ en az düşüm görülürken, büyütülmüş kesit alanında (KA3) en fazla düşüm görülmüştür (Çizelge 6). Çizelge 5'deki düşüm değerlerine varyans analizi yapılmış ve elde edilen sonuçları Çizelge 6'da verilmiştir. Seçilen tüm parametreler ve interaksiyonları arasında istatistiksel olarak \%1 seviyesinde anlamlı bir ilişki bulunmuştur.

Çizelge 5. Pompaların 40 ve $60 \mathrm{~m}^{3} \mathrm{~h}^{-1}$ debi değerlerinde elde edilen düşüm $(\mathrm{cm})$ seviyeleri

Table 5. Obtained drawdown (cm) levels in values 40 and $60 \mathrm{~m}^{3} \mathrm{~h}^{-1}$ flow rate of the pumps.

\begin{tabular}{|c|c|c|c|c|c|}
\hline $\mathrm{Q}\left(\mathrm{m}^{3} \mathrm{~h}^{-1}\right)$ & KA & $\mathrm{M}_{1}(\mathrm{~cm})$ & $\mathrm{M}_{2}(\mathrm{~cm})$ & $\mathrm{M}_{3}(\mathrm{~cm})$ & Debi ortalaması (Flow rate mean) \\
\hline \multirow{3}{*}{40} & $\mathrm{KA}_{1}$ & $29.77_{1}$ & $30.01_{\mathrm{hl}}$ & $34.96_{\mathrm{f}}$ & \multirow{3}{*}{$31.512 \mathrm{~b}$} \\
\hline & $\mathrm{KA}_{2}$ & $28.12_{j}$ & $33.00 \mathrm{~g}$ & $31.03 \mathrm{~h}$ & \\
\hline & $\mathrm{KA}_{3}$ & $30.79_{\mathrm{hl}}$ & $30.95_{\mathrm{hl}}$ & $34.98_{\mathrm{f}}$ & \\
\hline \multirow{3}{*}{60} & $\mathrm{KA}_{1}$ & $61.30 \mathrm{e}$ & $65.96 \mathrm{~cd}$ & $74.01 \mathrm{a}$ & \multirow{3}{*}{$67.72 \mathrm{a}$} \\
\hline & $\mathrm{KA}_{2}$ & $61.86_{\mathrm{e}}$ & $70.63 \mathrm{~b}$ & $70.85 \mathrm{~b}$ & \\
\hline & $\mathrm{KA}_{3}$ & $64.96 \mathrm{~d}$ & $67.0 c_{\mathrm{c}}$ & $72.91_{\mathrm{a}}$ & \\
\hline & & \multicolumn{3}{|c|}{$L S D=1.216$} & $\mathrm{LSD}=0.585$ \\
\hline \multirow{2}{*}{\multicolumn{2}{|c|}{ Pompa ort. (Pump mean) }} & $46.13 \mathrm{c}$ & $46.59 \mathrm{~b}$ & $53.12 \mathrm{a}$ & \\
\hline & & $\mathrm{LSD}=0.4965$ & & & \\
\hline
\end{tabular}

Çizelge 6. Pompalar düşüm seviyesi (cm) değerlerine uygulanan varyans analiz sonuçları

Table 6. The results of the analysis of variance applied to the drawdown level (cm) values of the pumps.

\begin{tabular}{|c|c|c|c|c|c|}
\hline & $\mathrm{SD}$ & KT & $\mathrm{KO}$ & $\mathrm{F}$ & \\
\hline Debi (Q) (Flow rate) & 1 & 17701.8 & 17701.8 & $65736.26^{* *}$ & \\
\hline Pompa (M) (Pump) & 2 & 440.1 & 220.1 & $817.17^{* *}$ & $\begin{array}{l}\text { Kesit alanı ortalamaları } \\
\text { (Mean cross-sectional area) }\end{array}$ \\
\hline $\begin{array}{l}\text { Kesit alanı (KA) } \\
\text { (Cross-section area) }\end{array}$ & 2 & 11.5 & 5.8 & $21.38^{* *}$ & $\mathrm{KA}_{1} 49.33 \mathrm{~b}$ \\
\hline $\mathrm{Q} \times \mathrm{M}$ & 2 & 75.9 & 38.0 & $141.01^{* *}$ & $\mathrm{KA}_{2} 49.24 \mathrm{~b}$ \\
\hline $\mathrm{Q} \times \mathrm{KA}$ & 2 & 5.6 & 2.8 & $10.44^{* *}$ & $\mathrm{KA}_{3} 50.26 \mathrm{a}$ \\
\hline $\mathrm{M} \times \mathrm{KA}$ & 4 & 108.0 & 27.0 & $100.23^{* *}$ & $\mathrm{LSD}=0.4965$ \\
\hline $\mathrm{Q} \times \mathrm{M} \times \mathrm{KA}$ & 4 & 5.7 & 1.4 & $5.32^{* *}$ & \\
\hline Hata (Error) & 36 & 9.7 & 0.3 & & \\
\hline Genel (General) & 53 & 18358.4 & & & \\
\hline
\end{tabular}

${ }^{* *} \mathrm{p}<0.01$

Pompalar arasında en az düşüm $28.12 \mathrm{~cm}$ değeri ile $\mathrm{M}_{1}$ pompasinda, en fazla düşüm $74.01 \mathrm{~cm}$ değeri ile $\mathrm{M}_{3}$ pompasinda görülmüştür. $\mathrm{Bu}$ düşüm değerleri arasında istatistiksel olarak bir farklılık olduğu Çizelge 5'in incelenmesinden anlaşılmaktadır. Varyans analizi sonucu, debi değerleri karşılaştırıldığında en yüksek düşüm değeri $60 \mathrm{~m}^{3} \mathrm{~h}^{-1}$ debi değerinde $(67.72 \mathrm{~cm})$ elde edilmiştir. Besleme kesit ağzı alanı değerleri incelendiğinde ise $\mathrm{KA}_{3}$ 'de en yüksek düşüm değerinin elde edildiği ve diğer besleme ağzı giriş kesit alanlarına ait değerler ile arasında istatistiki olarak bir farklılık olduğu saptanmıştır (Çizelge 6). İkili interaksiyon sonuçları Çizelge 7 ve 8'de verilmiştir. Üçlü interaksiyon incelendiğinde en yüksek düşüm değerinin $60 \mathrm{~m}^{3} \mathrm{~h}^{-1}$ debi değerinde $\mathrm{M}_{3} \mathrm{KA}_{1}$ ve $\mathrm{M}_{3} \mathrm{KA}_{3}$ kombinasyonlarında elde edildiği görülmektedir. $\mathrm{Bu}$ değerlerin diğer interaksiyonlarla arasında istatistiksel yönden bir farklılık olduğu, ancak kendi aralarında ise istatistiksel olarak anlamlı bir ilişkinin bulunmadiğını görülmüştür. Elde edilen sonuçları, yüksek debi değerinde pompanın fazla miktarda su çekmesine (Çizelge 8), anma çapı büyük olan pompada kuyu kesit alanını daralmasından dolayı pompaya su giriş hızlarının artmasıyla düşüm yüksekliği değerlerinin artmasının neden olduğu söylenebilir (Çizelge 8). Yukarıdaki değerlendirmelere bağlı olarak yüksek debi ve anma çapı değerinde en az düşüm değeri, pompanın orijinal kesit alanında görülmüsstür (Çizelge 5). Bunun doğal sonucu olarak $\mathrm{Q}_{2} \mathrm{KA}_{1} \mathrm{M}_{3}$ ve $\mathrm{Q}_{2} \mathrm{KA}_{3} \mathrm{M}_{3}$ kombinasyonlarında yüksek, $\mathrm{Q}_{2} \mathrm{KA}_{2} \mathrm{M}_{3}$ kombinasyonunda ise düşük değerde bulunmuştur.

$\mathrm{Bu}$ sonuçlara göre pompaların su girişi kesit alanlarının, pompa debilerine ve kuyu kesit alanına olan uyumunun önemli olduğu vurgulanabilir.

Pompalarda anma çapı ve giriş kesit alanının gürültü seviyesine etkisi

Pompalarda kuyu besleme borularının tam açı olduğu konumda ve üç anma çapında kuyuda meydana gelen gürültü seviyeleri (G) Çizelge 9'da verilmiştir.

Çizelgede de görüldüğü gibi ölçülen gürültü değerleri $72.6 \mathrm{dBA}$ ile $83.2 \mathrm{dBA}$ aralığında bir değişim göstermiştir. 
Çizelge 7. Pompalarda debi x kesit alanında elde edilen düşüm değeri interaksiyonuna uygulanan LSD testi sonuçları

Table 7. LSD test results applied to the drawdown value interaction obtained in flow $\mathrm{x}$ cross ${ }^{-}$ sectional area in pumps.

\begin{tabular}{|l|l|l|}
\hline \multirow{2}{*}{$\begin{array}{l}\mathrm{Q} \\
\left(\mathrm{m}^{3} \mathrm{~h}^{-1}\right)\end{array}$} & $\mathrm{KA}$ & $\begin{array}{l}\text { Debi ve kesit alanı } \\
\text { ortalamaları } \\
\text { (Flow and cross-sectional } \\
\text { area means) }\end{array}$ \\
\hline \multirow{3}{*}{40} & $\mathrm{KA}_{1}$ & $31.58_{\mathrm{c}}$ \\
\cline { 2 - 3 } & $\mathrm{KA}_{2}$ & $30.71_{\mathrm{d}}$ \\
\cline { 2 - 3 } & $\mathrm{KA}_{3}$ & $32.24_{\mathrm{c}}$ \\
\hline \multirow{3}{*}{60} & $\mathrm{KA}_{1}$ & $67.09_{\mathrm{b}}$ \\
\cline { 2 - 3 } & $\mathrm{KA}_{2}$ & $67.78_{\mathrm{ab}}$ \\
\hline & $\mathrm{KA}_{3}$ & $68.29_{\mathrm{a}}$ \\
\hline & & $\mathrm{LSD}=0.7022$ \\
\hline
\end{tabular}

Cizelge 8. Pompalarda debi $x$ anma çapı ve kesit alanı $x$ anma çapında elde edilen düşüm değeri interaksiyonuna uygulanan LSD testi sonuçları

Table 8. LSD test results applied to the drawdown value interaction obtained at flow $\boldsymbol{x}$ nominal diameter and cross sectional area $x$ nominal diameter in pumps.

\begin{tabular}{|l|l|l|l|}
\hline & $\mathrm{M}_{1}$ & $\mathrm{M}_{2}$ & $\mathrm{M}_{3}$ \\
\hline \multirow{2}{*}{$\mathrm{Q}_{1}$} & $29.55_{\mathrm{f}}$ & $31.32_{\mathrm{e}}$ & $33.65_{\mathrm{d}}$ \\
\cline { 2 - 4 } $\mathrm{Q}_{2}$ & $62.71_{\mathrm{c}}$ & $67.86 \mathrm{~b}$ & $72.59_{\mathrm{a}}$ \\
\hline & $\mathrm{LSD}=0.7022$ & $54.48_{\mathrm{a}}$ \\
\hline $\mathrm{KA}_{1}$ & $45.53_{\mathrm{f}}$ & $47.98_{\mathrm{e}}$ & $50.94_{\mathrm{c}}$ \\
\hline $\mathrm{KA}_{2}$ & $44.98_{\mathrm{f}}$ & $51.81_{\mathrm{b}}$ & $53.95_{\mathrm{a}}$ \\
\hline $\mathrm{KA}_{3}$ & $47.87_{\mathrm{e}}$ & $48.97_{\mathrm{d}}$ & \\
\hline & $\mathrm{LSD}=0.8600$ &
\end{tabular}

Çizelge 9. Pompalarda anma çapı, kesit alanı ve debinin gürültü seviyesine (dBA) etkisi Table 9. Effect of nominal diameter, cross ${ }^{-}$sectional area and flow rate on noise level (dBA) in pumps

\begin{tabular}{|c|c|c|c|c|c|c|c|c|c|}
\hline $\mathrm{Q}$ & $\mathrm{M}_{1}$ & & & $\mathrm{M}_{2}$ & & & $\mathrm{M}_{3}$ & & \\
\hline$\left(m^{3} h^{-1}\right)$ & $\mathrm{KA}_{1}$ & $\mathrm{KA}_{2}$ & $\mathrm{KA}_{3}$ & $\mathrm{KA}_{1}$ & $\mathrm{KA}_{2}$ & $\mathrm{KA}_{3}$ & $\mathrm{KA}_{1}$ & $\mathrm{KA}_{2}$ & $\mathrm{KA}_{3}$ \\
\hline 40 & 77.2 & 75.6 & 81.4 & 78.6 & 80.1 & 78.2 & 81.5 & 79.6 & 79.4 \\
\hline 45 & 79.1 & 73.2 & 82.2 & - & - & - & - & - & - \\
\hline 50 & 79.8 & 74.4 & 80.4 & 79.0 & 77.6 & 79.3 & - & - & - \\
\hline 55 & 78.4 & 73.4 & 80.2 & - & - & - & - & - & - \\
\hline 60 & 80.4 & 72.6 & 77.6 & 78.7 & 81.2 & 79.6 & 81.7 & 79.4 & 80.3 \\
\hline 70 & - & - & - & 79.0 & 78.4 & 77.2 & - & - & - \\
\hline 80 & - & - & - & 78.9 & 77.3 & 79.2 & 81.1 & 80.5 & 80.2 \\
\hline 90 & - & - & - & - & - & - & 83.2 & 81.0 & 80.4 \\
\hline
\end{tabular}

Çizelge 10. Pompaların 40 ve $60 \mathrm{~m}^{3} \mathrm{~h}^{-1}$ debi değerlerinde elde edilen gürültü değerleri

Table 10. Obtained noise level in values 40 and $60 \mathrm{~m}^{3} \mathrm{~h}^{-1}$ flow rate of the pumps.

\begin{tabular}{|c|c|c|c|c|c|c|}
\hline $\mathrm{Q}\left(\mathrm{m}^{3} \mathrm{~h}^{-1}\right)$ & $\mathrm{KA}$ & $\mathrm{M}_{1}(\mathrm{dBA})$ & $\mathrm{M}_{2}(\mathrm{dBA})$ & $\mathrm{M}_{3}(\mathrm{dBA})$ & \\
\hline \multirow{3}{*}{40} & \multirow{3}{*}{$\begin{array}{l}\mathrm{KA}_{1} \\
\mathrm{KA}_{2} \\
\mathrm{KA}_{3}\end{array}$} & $77.18 \mathrm{~g}$ & 78.60 ef & $81.51_{\mathrm{a}}$ & & \\
\hline & & $75.64 \mathrm{~h}$ & $80.13 \mathrm{~b}$ & $79.63 \mathrm{~cd}$ & \multicolumn{2}{|c|}{$\begin{array}{l}\text { Kesit alanı ortalamaları } \\
\text { (Mean cross-sectional area) }\end{array}$} \\
\hline & & $81.13 \mathrm{~b}$ & $78.13_{\mathrm{f}}$ & $79.39 \mathrm{~d}$ & $\mathrm{KA}_{1}$ & $79.69_{\mathrm{a}}$ \\
\hline \multirow{3}{*}{60} & \multirow{3}{*}{$\begin{array}{l}\mathrm{KA}_{1} \\
\mathrm{KA}_{2} \\
\mathrm{KA}_{3}\end{array}$} & $80.39_{b}$ & $78.73 \mathrm{e}$ & $81.67 \mathrm{a}$ & $\mathrm{KA}_{2}$ & $77.99_{\mathrm{c}}$ \\
\hline & & $72.60_{1}$ & $80.54 \mathrm{~b}$ & $79.39 \mathrm{~d}$ & $\mathrm{KA}_{3}$ & $79.40_{\mathrm{b}}$ \\
\hline & & $77.58 \mathrm{~g}$ & $79.63 \mathrm{~cd}$ & $80.31 \mathrm{~b}$ & \multicolumn{2}{|c|}{$\mathrm{LSD}=0.2156$} \\
\hline & & \multicolumn{3}{|c|}{$L S D=0.5056$} & & \\
\hline \multirow{2}{*}{\multicolumn{2}{|c|}{$\begin{array}{l}\text { Pompa ort. } \\
\text { (Pump mean) }\end{array}$}} & $77.42 \mathrm{c}$ & $79.3 \mathrm{~b}$ & 80.32 a & & \\
\hline & & \multicolumn{3}{|c|}{$\mathrm{LSD}=0.2064$} & & \\
\hline
\end{tabular}

Pompaların anma çaplarında, su giriş kesit alanlarında ve tüm akışın görüldüğü 40 ve $60 \mathrm{~m}^{3} \mathrm{~h}^{-1}$ debi değerlerinde elde edilen gürültü seviyeleri Çizelge 10'da verilmiştir.

Pompa anma çaplarına, su giriş kesit alanlarına ve tüm akışın görüldüğü 40 ve $60 \mathrm{~m}^{3} \mathrm{~h}^{-1}$ debi değerlerine varyans analizi yapılmış ve elde edilen sonuçları Çizelge 11'de verilmiştir. Çizelgenin incelenmesiyle debi parametresi hariç diğer seçilen parametreler ve interaksiyonları istatistiksel olarak \%1 seviyesinde anlamlı bir ilişki bulunmuştur.
Pompalar arasında en fazla gürültü seviyesi $81.67 \mathrm{dBA}$ değeri $\mathrm{M}_{3}$ pompasinda, en az ise $72.60 \mathrm{dBA}$ değeri ile $\mathrm{M}_{1}$ pompasında görülmüştür. $\mathrm{Bu}$ gürültü değerleri arasında istatistiksel olarak bir farklılık olduğu Çizelge 11'in incelenmesinden anlaşılmaktadır. Varyans analizi sonucu besleme kesit ağzı alanı değerleri incelendiğinde $\mathrm{KA}_{1}$ 'de en yüksek gürültü seviyesinin elde edildiği ve diğer besleme ağzı giriş kesit alanlarına ait değerler ile arasında istatistiki olarak bir farklılık belirlenmiştir (Çizelge 11). 
Çizelge 11. Pompaların gürültü seviyesi değerlerine uygulanan varyans analiz sonuçları

Table 11. Variance analysis results applied to the noise level values of the pumps

\begin{tabular}{|c|c|c|c|c|}
\hline & $\mathrm{SD}$ & $\mathrm{KT}$ & $\mathrm{KO}$ & $\mathrm{F}$ \\
\hline $\begin{array}{l}\text { Pompa (M) } \\
\text { (Pump) }\end{array}$ & 2 & 879.51 & 439.75 & $653.88 * *$ \\
\hline Kesit alanı (KA) & & & & \\
\hline $\begin{array}{l}\text { (Cross'section } \\
\text { area) }\end{array}$ & 2 & 346.76 & 175.38 & $257.80 * *$ \\
\hline $\begin{array}{l}\text { Debi }(\mathrm{Q}) \\
\text { (Flow rate) }\end{array}$ & 1 & 1.09 & 1.09 & 1.63 \\
\hline $\mathrm{M} \times \mathrm{KA}$ & 4 & 1134.46 & 283.62 & $421.71^{* *}$ \\
\hline$P \times Q$ & 2 & 104.64 & 52.32 & $77.80 * *$ \\
\hline$K A \times Q$ & 2 & 129.33 & 64.66 & $96.15^{* *}$ \\
\hline$M \times K A \times Q$ & 4 & 419.87 & 104.97 & $156.08^{* *}$ \\
\hline Hata & 612 & 411.59 & 0.67 & \\
\hline Genel & 629 & 3427.27 & & \\
\hline
\end{tabular}

${ }^{* *} \mathrm{p}<0.01$

İkili interaksiyon sonuçları Çizelge 12 ve 13'de verilmiştir. Üçlü interaksiyon incelendiğinde en yüksek gürültü değerinin $\mathrm{M}_{3} \mathrm{KA}_{1}$ kombinasyonlarının 40 ve $60 \mathrm{~m}^{3} \mathrm{~h}^{-1}$ debi değerinde elde edildiği görülmektedir. Bu değerlerin diğer interaksiyonlarla arasında istatistiksel yönden bir farklılık olduğu, ancak kendi aralarında ise istatistiksel olarak anlamlı bir ilişkinin bulunmadığı görülmüştür. Elde edilen sonuçları, küçültülmüş giriş kesit ağzından yüksek debi çekilmesine (Çizelge 12), anma çapı büyük olan pompada kuyu kesit alanını daralmasından dolayı pompaya su giriş hızlarının artmasıyla gürültü değerlerinin artmasının neden olduğu söylenebilir (Çizelge 13). Gürültü seviyesinin $72.6 \mathrm{dBA}$ değeri ile en düşük $\mathrm{M}_{1}$ pompasında olmasını ise pompa anma çapına, orijinal kesit alanına ve pompanın optimum debi değerine yakın debide çalışmasına bağlayabiliriz. Çalışır ve ark.,(2006) çalışmalarında denemeye alınan yatay milli santrifüj pompaların optimum debilerinde en düşük gürültü seviyelerinin elde edildiğini açıklamışlardır.
Çizelge 12. Pompalarda debi x kesit alanında elde edilen gürültü değeri interaksiyonuna uygulanan LSD testi sonuçları

Table 12. LSD test results applied to the noise value interaction obtained in flow rate $\mathrm{x}$ cross sectional area in pumps.

\begin{tabular}{|c|c|c|}
\hline $\begin{array}{l}\mathrm{Q} \\
\left(\mathrm{m}^{3} \mathrm{~h}^{-1}\right)\end{array}$ & $\mathrm{KA}$ & $\begin{array}{l}\text { Debi - kesit alanı } \\
\text { ortalamaları } \\
\text { (Flow and cross }{ }^{-} \\
\text {sectional area means) }\end{array}$ \\
\hline \multirow{3}{*}{40} & \multirow{3}{*}{$\begin{array}{l}\mathrm{KA}_{1} \\
\mathrm{KA}_{2} \\
\mathrm{KA}_{3}\end{array}$} & $79.10 \mathrm{c}$ \\
\hline & & $78.46 \mathrm{~d}$ \\
\hline & & $79.63 \mathrm{~b}$ \\
\hline \multirow{4}{*}{60} & \multirow{4}{*}{$\begin{array}{l}\mathrm{KA}_{1} \\
\mathrm{KA}_{2} \\
\mathrm{KA}_{3} \\
\end{array}$} & $80.26_{a}$ \\
\hline & & $77.51 \mathrm{e}$ \\
\hline & & $79.17_{\mathrm{c}}$ \\
\hline & & $\mathrm{LSD}=0.2919$ \\
\hline
\end{tabular}

Çizelge 13. Pompalarda debi x anma çapı ve kesit alanı $\mathrm{x}$ anma çapında elde edilen gürültü değeri interaksiyonuna uygulanan LSD testi sonuçları

Table 13. LSD test results applied to the noise value interaction obtained at flow $\mathrm{x}$ nominal diameter and cross sectional area $x$ nominal diameter in pumps.

\begin{tabular}{|l|l|l|l|}
\hline & $\mathrm{M}_{1}$ & $\mathrm{M}_{2}$ & $\mathrm{M}_{3}$ \\
\hline \multirow{2}{*}{$\mathrm{Q}_{1}$} & $78.07 \mathrm{~d}$ & $78.95_{\mathrm{c}}$ & $80.18_{\mathrm{a}}$ \\
\cline { 2 - 4 } $\mathrm{Q}_{2}$ & $76.85 \mathrm{e}$ & $79.63 \mathrm{~b}$ & $80.46_{\mathrm{a}}$ \\
\hline & $L S D=0.2919$ \\
\hline $\mathrm{KA}_{1}$ & $78.78 \mathrm{e}$ & $78.67 \mathrm{e}$ & $81.59_{\mathrm{a}}$ \\
\hline $\mathrm{KA}_{2}$ & $74.12_{\mathrm{f}}$ & $80.33 \mathrm{~b}$ & $79.51_{\mathrm{cd}}$ \\
\hline $\mathrm{KA}_{3}$ & $79.48 \mathrm{~d}$ & $78.88 \mathrm{e}$ & $79.85 \mathrm{c}$ \\
\hline & $L S D=0.3575$ \\
\hline
\end{tabular}

Pompalarda anma çapı ve giriş kesit alanının güç (N) üzerine etkisi

Pompalarda kuyu besleme borularının tam açık olduğu konumda ve üç anma çark çapında ölçülen şebekeden çekilen güç (N) değerleri Çizelge 14'de verilmiştir.

Çizelge 14. Pompalarda anma çapı, kesit alanı ve debinin şebekeden çekilen güce (kW) etkisi

Table 14. The effect of the pumps the nominal diameter, cross-sectional area and flow rates to the power drawn from the mains $(k W)$

\begin{tabular}{llllllllll}
\hline $\mathrm{Q}$ & $\mathrm{M}_{1}$ & & \multicolumn{3}{c}{$\mathrm{M}_{2}$} & & & $\mathrm{M}_{3}$ & \\
\hline$\left(\mathrm{m}^{3} \mathrm{~h}^{-1}\right)$ & $\mathrm{KA}_{1}$ & $\mathrm{KA}_{2}$ & $\mathrm{KA}_{3}$ & $\mathrm{KA}_{1}$ & $\mathrm{KA}_{2}$ & $\mathrm{KA}_{3}$ & $\mathrm{KA}_{1}$ & $\mathrm{KA}_{2}$ & $\mathrm{KA}_{3}$ \\
\hline 40 & 4.8 & 5.1 & 4.9 & 4.7 & 5.1 & 4.7 & 6.7 & 6.4 & - \\
45 & 5.0 & 5.2 & 5.0 & - & - & - & - & - & - \\
50 & 5.1 & 5.2 & 5.0 & 5.0 & 4.8 & 4.9 & - & - & - \\
55 & 5.3 & 5.2 & 5.1 & - & - & - & - & - & - \\
60 & 5.2 & 5.1 & 5.3 & 5.4 & 5.6 & 5.1 & 7.1 & 7.0 & 7.2 \\
70 & - & - & - & 5.6 & 5.7 & 5.1 & - & - & - \\
80 & - & - & - & 5.8 & 5.6 & 5.6 & 8.0 & 7.8 & 7.8 \\
90 & - & - & - & - & - & - & 8.2 & 8.0 & 8.1 \\
\hline
\end{tabular}


Pompalarda anma çapı ve giriş kesit alanının toplam dinamik yükseklik (TDY) üzerine etkisi

Kuyu besleme borusu vanalarının tam açık olduğu konumda pompaların üç anma çapında $\left(\mathrm{M}_{1}, \mathrm{M}_{2}\right.$ ve $\left.\mathrm{M}_{3}\right)$ her birinin üç su girişi kesit alanında $\left(\mathrm{KA}_{1}, \mathrm{KA}_{2}\right.$ ve $\left.\mathrm{KA}_{3}\right)$ ve farkl debilerde (Q) hesaplanan toplam dinamik yükseklik değerleri Çizelge 15 'de verilmiştir.

Çizelge 15 incelendiğinde her üç pompa anma çapı ve giriş kesit alanı seviyelerinde debinin artması ile TDY değerleri azalmıştır. Bu değişimin pompaların TDY-Q karakteristiğine uygun davrandığ 1 yönünde değerlendirilmiştir. Pompa anma çapı arttıkça
TDY'de artış eğilimi göstermiştir. Pompaların en yüksek debi değerlerinde kesit alanları bakımında orijinal kesit alanında (KA2) TDY değeri en düşük çıkmıştır.

Pompalarda anma çapı ve giriş kesit alanının v1 ve v2 hızlarina etkisi

Kuyu besleme borularının tam açık olduğu konumda pompaların üç anma çapında $\left(\mathrm{M}_{1}, \mathrm{M}_{2}\right.$ ve $\left.\mathrm{M}_{3}\right)$ her birinin üç su giriş ağzı kesit alanında $\left(\mathrm{KA}_{1}, \mathrm{KA}_{2}\right.$ ve $\left.\mathrm{KA}_{3}\right)$ ve farklı debilerde (Q) ölçülen $\mathrm{v}_{1}$ ve $\mathrm{v}_{2}$ hız değişimleri Çizelge 16 ve 17 'de verilmişstir.

Çizelge 15. Pompalarda anma çapı, kesit alanı ve debinin TDY $(\mathrm{kPa})$ üzerine etkisi

Table 15. Effect of the pumps nominal diameter, cross-sectional area and flow rates on TDY (kPa).

\begin{tabular}{llllllllll}
\hline $\mathrm{Q}$ & $\mathrm{M}_{1}$ & \multicolumn{7}{c}{$\mathrm{M}_{2}$} & \multicolumn{3}{l}{$\mathrm{M}_{3}$} \\
\hline$\left(\mathrm{m}^{3} \mathrm{~h}^{-1}\right)$ & $\mathrm{KA}_{1}$ & $\mathrm{KA}_{2}$ & $\mathrm{KA}_{3}$ & $\mathrm{KA}_{1}$ & $\mathrm{KA}_{2}$ & $\mathrm{KA}_{3}$ & $\mathrm{KA}_{1}$ & $\mathrm{KA}_{2}$ & $\mathrm{KA}_{3}$ \\
\hline 40 & 159.3 & 162.1 & 156.9 & 138.4 & 144.4 & 143.8 & 178.4 & 201.6 & 194.3 \\
45 & 147.2 & 146.4 & 143.3 & - & - & - & - & - & - \\
50 & 130.0 & 129.2 & 126.3 & 131.2 & 130.0 & 129.8 & - & - & - \\
55 & 115.1 & 111.2 & 106.3 & - & - & - & - & - & - \\
60 & 94.3 & 90.9 & 92.7 & 123.3 & 120.7 & 119.3 & 164.4 & 172.4 & 167.3 \\
70 & - & - & - & 111.1 & 106.3 & 105.2 & - & - & - \\
80 & - & - & - & 96.6 & 88.8 & 93.0 & 146.5 & 145.3 & 143.5 \\
90 & - & - & - & - & - & - & 135.3 & 132.5 & 134.8 \\
\hline
\end{tabular}

Cizelge 16. Pompalarda anma çapı, kesit alanı ve debinin vı hızına $\left(\mathrm{ms}^{-1}\right)$ etkisi

Table 16. Effect of the pumps nominal diameter, cross 'sectional area and flow rate of on speed $\mathrm{v}_{1}\left(\mathrm{~ms}^{-1)}\right.$

\begin{tabular}{llllllllll}
\hline $\mathrm{Q}$ & $\mathrm{M}_{1}$ & \multicolumn{9}{c}{$\mathrm{M}_{2}$} & & & $\mathrm{M}_{3}$ & & \\
\hline$\left(\mathrm{m}^{3} \mathrm{~h}^{-1}\right)$ & $\mathrm{KA}_{1}$ & $\mathrm{KA}_{2}$ & $\mathrm{KA}_{3}$ & $\mathrm{KA}_{1}$ & $\mathrm{KA}_{2}$ & $\mathrm{KA}_{3}$ & $\mathrm{KA}_{1}$ & $\mathrm{KA}_{2}$ & $\mathrm{KA}_{3}$ \\
\hline 40 & 0.18 & 0.18 & 0.18 & 0.18 & 0.19 & 0.19 & 0.20 & 0.20 & - \\
45 & 0.20 & 0.20 & 0.20 & - & - & - & - & - & - \\
50 & 0.22 & 0.22 & 0.22 & 0.23 & 0.23 & 0.24 & - & - & - \\
55 & 0.24 & 0.24 & 0.24 & - & - & - & - & - & - \\
60 & 0.26 & 0.27 & 0.26 & 0.28 & 0.28 & 0.28 & 0.30 & 0.30 & 0.31 \\
70 & - & - & - & 0.33 & 0.32 & 0.33 & - & - & - \\
80 & - & - & - & 0.37 & 0.37 & 0.38 & 0.40 & 0.40 & 0.40 \\
90 & - & - & - & - & - & - & 0.45 & 0.45 & 0.46 \\
\hline
\end{tabular}

Çizelge 17. Pompalarda anma çapı, kesit alanı ve debinin v2 hızına $\left(\mathrm{m} \mathrm{s}^{-1}\right)$ etkisi

Table 17. Effect of the pumps nominal diameter, cross sectional area and flow rate of on speed $v_{1}\left(\mathrm{~ms}^{-1}\right)$

\begin{tabular}{llllllllll}
\hline $\mathrm{Q}$ & $\mathrm{M}_{1}$ & \multicolumn{3}{c}{$\mathrm{M}_{2}$} & \multicolumn{5}{c}{$\mathrm{M}_{3}$} \\
\hline$\left(\mathrm{m}^{3} \mathrm{~h}^{-1}\right)$ & $\mathrm{KA}_{1}$ & $\mathrm{KA}_{2}$ & $\mathrm{KA}_{3}$ & $\mathrm{KA}_{1}$ & $\mathrm{KA}_{2}$ & $\mathrm{KA}_{3}$ & $\mathrm{KA}_{1}$ & $\mathrm{KA}_{2}$ & $\mathrm{KA}_{3}$ \\
\hline 40 & 2.95 & 2.33 & 1.92 & 1.54 & 1.23 & 1.03 & 0.81 & 0.66 & 0.56 \\
45 & 3.30 & 2.61 & 2.16 & - & - & - & - & - & - \\
50 & 3.67 & 2.90 & 2.39 & 1.93 & 1.54 & 1.29 & - & - & - \\
55 & 4.04 & 3.19 & 2.64 & - & - & - & - & - & 0.93 \\
60 & 4.40 & 3.49 & 2.88 & 2.31 & 1.85 & 1.54 & 1.23 & 0.99 & - \\
70 & - & - & - & 2.70 & 2.16 & 1.80 & - & - & 1.11 \\
80 & - & - & - & 3.09 & 2.47 & 2.06 & 1.65 & 1.32 & 1.48 \\
90 & - & - & - & - & - & - & 1.85 & 1.48 & 1.25 \\
\hline
\end{tabular}

Pompaların anma çapı ve giriş kesit alanlarında debi attıkça vı hızı yükselmiştir. Sabit debilerde ve her üç anma çapında, kesit alanının artması vı hızı üzerinde etkili olmamıştır. Ancak sabit debilerde ve her üç kesit alanında pompa anma çapının artması vi hızı değerlerini artırmıştır. Bunun nedeni vı hızının, teçhiz borusu ile pompa grubu anma çapı arasında kalan halka alandan ölçülmesine bağlanabilir. Kesit alanının küçülmesi v1 hız değerlerini yükseltmiştir. Çünkü kuyuda sabit iç çapında teçhiz borusu kullanılmış ve pompa anma çapının artmasıyla v1 hızının ölçüldüğü halkanın alanı küçülmüştür. 
Çizelgeler 17 incelendiğinde pompaların anma çapı ve giriş kesit alanlarında debi attıkça v2 hızı değerleri yükselmiştir. Sabit debilerde ve her üç anma çapında, pompa emme ağzı giriş kesit alanının artması v2 hızını azaltmıştır. Benzer şekilde sabit debilerde ve her üç kesit alanında da pompa anma çapının arttıkça v2 hızları küçülmüştür. Bunun nedeni v2 hızının pompa su girişi ağzından ölçülmesine ve büyük anma çaplı pompaların giriş kesitlerinin daha büyük olması ile açıklanabilir.

Pompa kolon borusunda ölçülen hız ( $\left.v_{1}\right)$ ile pompa giriş ağzında ölçülen hız ( $\left.v_{2}\right)$ değerlerinin yükselmesi, akışın sürekli ve kütlenin korunumu kanununa uygun davrandığını göstermektedir (Çengel ve Cimbala, 2008).

\section{SONUÇ ve ÖNERILLER}

Pompaların tüm anma çaplarında ve giriş kesit alanlarında debi arttıkça düşüm değeri artmıştır. Sabit debide pompa anma çapının artması düşüm seviyesini yükseltmiştir. Aynı şekilde sabit kesit alanında pompa anma çapının artması düşüm değerlerinin artırmıştır (Çizelge 8). Pompa anma çaplarının tümünde kesit alanlarındaki ortalama düşüm değerleri istatistiksel olarak $\mathrm{KA}_{1}$ ve $\mathrm{KA}_{2}$ 'de farksız iken $\mathrm{KA}_{3}$ 'de farklı çıkmıştır. Kesit alanları bakımından düşüm değerlerini sadece KA3'ün etkilediği görülmüştür (Çizelge 6).

Pompa anma çapı ile kuyu teçhiz borusu arasındaki uyumun düşüm üzerine etkisinin olduğu saptanmıştır. Kuyu için pompa seçiminde düşük çaplı pompa seçimi düşüm seviyesinin de az olmasına neden olacaktır.

Pompa anma çapının artması ortalama gürültü seviyelerini artırmıştır (Çizelge 10). Pompa su giriş kesit alanını değiştirmek gürültü seviyesi üzerine olumsuz etkisi olmuştur. Pompaların gürültü değişim sevilerin belirlenmesi, pompanın kavitasyon, çark aşınması gibi fiziksel durumlara maruz kalmasında oluşan ani gürültü değişimlerinin tespiti için önemlidir. Pompaların farklı çalışma aralıklarında gürültü değişimleri belirlenmiştir.

Bu çalışma ile pompa anma çapı ve kuyu teçhiz borusu arasındaki ilişki pompa işletme karakteristikleri yönünden incelenmiş olup, en uygun pompa seçimi için bir yol göstermiş̧tir.

\section{TEŞEKKÜR}

Bu çalışma, Türkiye Bilimsel ve Teknik Araştırma Kurumu (TÜBİTAK, Proje No: 2130140) tarafindan desteklenmiştir. $\mathrm{Bu}$ çalışmaya katkıda bulunan merhum Prof.Dr. Sedat ÇALIŞIR Hocamıza teşekkür ederiz.

\section{Çıkar Çatışması Beyanı}

Makale yazarları aralarında herhangi bir çıkar çatışması olmadığını beyan ederler.
Araştırmacıların Katkı Oranı Beyan Özeti

Yazarlar makaleye eşit oranda katkı sağlamış olduklarını beyan ederler.

\section{KAYNAKÇA}

Akpınar K 1999. Su Sondaj Kuyularının Açılması ve İşletilmesi Sırasında Çıkan Sorunlar ve Çözümleri. İller Bankası Makine ve Sondaj Dairesi Başkanlığı, Ankara, 696 sy.

Anonim 2002. Rotodinamik Pompalar-Hidrolik Performans Kabul Deneyleri Sinif 1 ve Sinif 2 (TS EN ISO 9906). Türk Standardları Enstitüsü, Ankara.

Atmaca S 1998. Dalgıç Pompalara Uygulanan Pompa Kabul Deneyleri. 3. Pompa Kongresi, 24-26 Eylül 1998, İstanbul.

Baysal K 1979. Tam Santrifüj Pompalar: Hesap, Çizim ve Konstrüksiyon Özellikleri. İstanbul Teknik Üniversitesi, 24 sy.

Boonstra H, Soppe R 2006. Well Design and Construction, In: The Handbook Of Groundwater Engineering, Eds: Delleur, J. W., CRC Press Taylor \& Francis Group: Alterra-ILRI, The Netherlands The Netherlands. 420-450.

Çalışır S, Konak M 1998. Konya Bölgesinde Bazı Derin Kuyu Pompaj Tesislerinde Başarı Derecesinin Saptanması. 3. Pompa Kongresi, 24-26 Eylül 1998, İstanbul.

Çalışır S, Aydın C, Mengeş HO 2006. Derin Kuyu Pompaj Tesislerinde Titreşim Hızı Ve Gürültü Düzeyinin Belirlenmesi. Selçuk Tarım Bilimleri Dergisi, 20 (38): 49-54.

Çalışır S 2009. Sulamada Pompaj Tesisleri (Tarım Makineleri Kitabı. Edt:Ergüneş G, Nobel Yayın Dağıtım, Ankara) 351-413.

Çengel YA, Cimbala JM 2008. Akışkanlar Mekaniği: Temelleri ve Uygulamaları, Güven Kitabevi, 817 sy.

Driscoll F 2010. Kuyu Hidroliği. Çeviri: Özkan AF, DSI, Ankara, 88 sy.

Ertöz A 1996. Yer Altı Suları Pompaj Ekonomisi ve Pompa Seçimine Etki Eden Faktörler. 2. Pompa Kongresi, 3-5 Nisan 1996, İstanbul.

Hanson B 2000. Irrigation Pumping Plants (UC Irrigation and Drainage Specialist. Department of Land, Air and Water Resources, University of California, Davis) 69-73.

Karassik IJ, Messina JP, Cooper P, Heald CC 2001. Pump handbook. McGraw-Hill New York, 1824 p.

Kurt M, Çalışır S 2017. Derin Kuyu Pompalarında Anma Çapının Kuyudaki Su Seviyesinin Düşümüne Etkisi. Selçuk Tarım Bilimleri Dergisi, 3 (2): 291-297.

Schulz H 2013. Die Pumpen: Arbeitsweise Berechnung Konstruktion. Springer-Verlag.

Tezer E 1978. Sulamada Pompaj Tesisleri (proje, seçim ve işletme yöntemleri), Cilt 1-2-3. Çukurova Üniversitesi Ziraat Fakültesi Yayınları, Adana. 